\title{
Developmental Outcome in Children with Intrauterine Exposure to Substances
}

\author{
H.-C. Steinhausen B. Blattmann F. Pfund \\ Department of Child and Adolescent Psychiatry, University of Zürich, Zürich, Switzerland
}

\begin{abstract}
Key Words
Substance abuse disorder • Mothers, substance abuse • Offspring of substance-dependent mothers - Prenatal exposure to cocaine $\cdot$ Children, developmental outcome
\end{abstract}

\begin{abstract}
The developmental outcome of children born to Swiss substance-dependent mothers in a residential treatment program was studied in a sample of 61 children ranging from infancy to preadolescence (mean age $=5.10, \mathrm{SD}=3.10$ years) by use of age-appropriate tests of intelligence. A large list of biological and psychosocial risk factors was tested for associations with outcome in the children. The mean profile of test findings across all age ranges was significantly lower than population norms and there was an excess of children with subnormal intellectual functioning. Performance IQ was associated negatively only with intrauterine substance exposure, but with none of the other risk factors. Among the various substances, predominantly heroin or methadone were responsible for this association when controls for nicotine or cannabis consumption were made. The study provides further evidence that intrauterine exposure to heroin and methadone negatively affects the developmental outcome in the offspring of substance-dependent mothers.
\end{abstract}

Copyright $\odot 2007$ S. Karger AG, Basel
(C) 2007 S. Karger AG, Basel

1022-6877/07/0132-0094\$23.50/0

Fax +4161306 1234

E-Mail karger@karger.ch

www.karger.com
Accessible online at:

www.karger.com/ear

\section{Introduction}

The offspring of substance-dependent mothers are exposed to various risks. Besides genetic risk factors that might predispose the child to later substance abuse, prenatal risk factors may also have an effect on development. In contrast to a fully expressed fetal alcohol syndrome, most other street substances like cocaine or heroin do not lead to dysmorphic features in the child. However, the development of the exposed child may be severely impaired due to prenatal risk factors in combination with the various postnatal risk factors resulting from the hazardous life circumstances of substance-dependent parents.

Various studies predominantly from the United States, with a strong predominance of subjects from ethnic minorities, have studied the cognitive outcome of children who had been intrauterinely exposed to various substances. In these studies the effects of cocaine, heroin, and multiple substances abuse have been addressed.

Controversial findings have been obtained in studies on the effects of cocaine, with one study finding transient effects in infancy [1] and the majority of studies finding no effects either during infancy, pre-school or early school age [2-8]. Most studies explain low test scores in these children by low socioeconomic status.

Motor development after cocaine exposure has also been shown to be not affected in some studies $[3,5,9]$ whereas others found dose-related motor deficits [10-12]. One study revealed an increased risk for neuromotor dysfunction at the age of 4 months [13] and another study

H.-C. Steinhausen

Department of Child and Adolescent Psychiatry, University of Zürich

Neumünsterallee 9/Postfach, CH-8032 Zürich (Switzerland)

Tel. +41 43499 2730, Fax +41 434992602

E-Mail steinh@kjpd.unizh.ch 
pointed to transient lower motor functioning at preschool age [4].

In addition, various studies indicate impaired language development and specific receptive language difficulties [14-17]. A recent study based on a large at-risk sample found no association of infant prenatal exposure to cocaine and to opiates with mental or motor deficits after controlling for birth weight and environmental risks [18].

Similarly, there are discrepant findings on the effects of intrauterine exposure to opiates and heroin. Differences between exposed children and controls have been obtained only for selected subgroups and specific subtests of measures of cognitive development in infants [19], and in school-aged children depending on the domestic status [20], whereas motor functioning has been found to be impaired only in 8 - to 10 -year-old children but not in older children [21].

The findings on the effects of multiple substance abuse during pregnancy are more consistent. A majority of studies point to negative effects on cognitive development in infants and pre-schoolers [22-26] whereas others emphasize the deprived socioeconomic background as the main causal factor [26-29]. Some studies revealed important mediators to be operant, e.g. lack of early intervention [30], coexistent maternal depression in pregnancy [31] or environmental risks [32]. In addition, various studies found deficits in various domains of motor functioning $[10,23$, 30]. Difficulties in language development have also been shown by various studies $[24,26,28]$. No difficulties in cognitive development have been observed in school-aged children of methadone-maintained mothers [33].

Given the predominance of studies from the United States including large groups of subjects from ethnic minorities and/or severely deprived socioeconomic backgrounds and a strong focus on mostly rather young children, it seemed worthwhile to study the cognitive development of a group of indigenous Swiss subjects with a wider age range from infancy to preadolescence. Using age-appropriate cognitive and motor tests the study particularly aimed at identifying the relevant predictors of developmental outcome in these children.

\section{Method}

\section{Subjects}

The 61 subjects of the present study were recruited from two Swiss residential treatment programs for substance-dependent mothers and their children of various ages. Both mothers and children were assessed during or shortly after the treatment program.
Table 1. Sample and clinical characteristics $(n=61)$

\begin{tabular}{lc}
\hline Age of the children, years & \\
Mean & 5.10 \\
SD & 3.10 \\
\hline Gender & \\
Male & $28(45.9 \%)$ \\
Female & $33(54.1 \%)$ \\
\hline Domestic arrangement & \\
Family & $13(21.3 \%)$ \\
Single mother & $22(35.2 \%)$ \\
Foster family & $3(4.9 \%)$ \\
Residential treatment program & $20(32.8 \%)$ \\
Institution/with relatives & $3(4.9 \%)$ \\
\hline Maternal age, years & \\
Mean & 31.2 \\
SD & 4.3 \\
\hline Maternal IQ & \\
Mean & 101.1 \\
SD & 13.9 \\
\hline Maternal education & \\
No profession & $18(30.5 \%)$ \\
Unskilled & $11(18.6 \%)$ \\
Skilled & $29(50.9 \%)$ \\
\hline Type of substance abuse during pregnancy & \\
Nicotine & $49(81.7 \%)$ \\
Heroin & $34(56.7 \%)$ \\
Cannabis & $23(38.3 \%)$ \\
Methadone & $18(30.0 \%)$ \\
Cocaine & $17(28.3 \%)$ \\
Alcohol & $12(20.0 \%)$ \\
Other & $17(28.3 \%)$ \\
\hline Number of substances used during pregnancy & \\
Mean & 2.8 \\
SD & 1.9 \\
\hline & \\
\hline & \\
\hline
\end{tabular}

At the time of assessment a total of 23 mother-child pairs were participating in the residential treatment program, 32 had completed the intervention, 3 had dropped out of treatment, and 3 participated in other programs. As can be seen from table 1, the age range of the children is wide and covers both very young and older children. There were 22 (36\%) children up to 3 years of age, 12 children (20\%) between 4 and 6 years of age, and 27 children (44\%) between 6 and 14 years of age. There was a slight excess of females and only a minority of the children lived with both parents. The proportion of single mothers was large and a third of the children stayed with the residential treatment programs at the time of the assessment. Few children lived in foster families or in institutions.

The mothers were on average in their early 30 s and had a longstanding substance-abuse history. All mothers were indigenous Swiss. The mothers of 52 children (83.8\%) had been abusing substance during pregnancy. At this time, nicotine, heroin, cannabis, 
methadone, cocaine, and alcohol had been abused in descending frequency and on average two to three different substances had been abused. Given this variety, three different types of intrauterine substance exposure (IUSE) were differentiated: (a) IUSE 1, any substance exposure, (b) IUSE 2, any substance exposure without considering nicotine as a risk factor, and (c) IUSE 3, any substance exposure without considering nicotine and cannabis as a risk factor. Furthermore, there were 9 children (1 younger than 3 years of age and 8 over 3 years of age) who had not been exposed to substances during pregnancy. These subjects served as a control group for the effects of IUSE.

At birth, 45 (73.8\%) of the neonates had been suffering from at least one risk as described below in the procedure section. Premature birth had occurred in $6(9.8 \%)$ and there had been a reduced birth weight $(<2,500 \mathrm{~g})$ in a total of $9(14.8 \%)$ of the children.

\section{Procedure}

During the study time period, developmental outcome in the children was tested with age-appropriate standardized tests including the Bayley Scales of Infant Development [34], the Wechsler Pre-school and Primary Scale of Intelligence (WPPSI, German adaptation by Eggert (1975) [35]), and the Wechsler Intelligence Scale for Children Revision (WISC-R, Swiss-German adaptation by Bründler and Schallberger (1988) [36]). From the Bayley test [34] both the mental and the motor scale score and from the WPPSI and the WISC-R both the verbal and the performance IQ (mean $=100, S D=15)$ were derived. In addition, a verbal total IQ and a performance total IQ across the WPPSI and the WISC-R were computed. Bayley test findings were compared to norms with age adjusted for weeks of prematurity.

Data on the various risks factors were predominantly obtained from structured interviews with the mothers. First, a detailed substance history asked for the type and number of substances that had been used during pregnancy. An index of prenatal substance exposure was constructed by summing up the various substances with each substance having the same weight. In addition, the interview with the mother assessed the following prenatal risk factors: bleeding, hypertension, persistent and severe vomiting, infections, radiological examinations or treatments, medications, surgical interventions including anesthesia, severe mental suffering, hospitalization due to imminent miscarriage, severe illness, previous miscarriages, previous premature termination of pregnancy, and previous complicated pregnancies. Furthermore, clinical birth records were obtained for all participating children and checked for prematurity, small for gestational age and neonatal withdrawal symptoms.

From the entire set of pre- and perinatal data, a pre- and perinatal risk factor index was calculated by summing up the various items with each having the same weight. In a similar way the following items were summed up for a neonatal risk factor index: failure to suck, seizures, treatment in an isolette, neonatal jaundice including phototherapy, intensive care, fractures due to delivery, laboratory pathology, life-threatening diseases, other complications. Withdrawal symptoms were coded as an independent risk.

Further sections of the structured interview dealt with parental educational status, current domestic arrangements and the number of family members and relatives to whom the child had close relationships. From the latter an index of close relationships was calculated by summing up the following items: mother, fa- ther, stepfather, cohabiting partner of the mother, grandmother, grandfather, foster mother, foster father, other relatives.

Finally, the interview covered various psychosocial risk factors including separation of the parents, single motherhood, death of the father, HIV infection of the mother and/or father, preceding institutional care, current institutional care, substance abuse after pregnancy, and current substance abuse. Again an index was calculated by summing up the individual items with each having the same weight.

Intelligence of the mother was assessed with a brief estimation test because extended testing was not possible. The Figure-Connection Test by Oswald and Roth [37] has similarities with the Trail Making Test of Reitan [38] and measures cognitive speed of processing. It takes only 5-10 min and allows the calculation of an IQ based on a large German standardization sample. Maternal educational status was rated according to academic training and ranged from uncompleted academic training to university graduation.

Statistical analyses tested for differences of the outcome measures from population norms by t tests and for univariate associations of the various risk factors with the three child outcome measures by calculation of Mann-Whitney tests and correlation coefficients. Additional multiple regression analyses were computed in order to identify those factors that carry independent risks on outcome.

\section{Results}

The mean test profile of subjects with IUSE 1 across all developmental outcome variables in the various subgroups in the various subgroups is shown in table 2. Clearly, there is an excess of low functioning subjects on both Bayley scores in infancy. The low WPPSI performance IQ and the verbal total IQ deviate significantly from the population norms. Even for the small subgroup of children with a WPPSI performance IQ, the proportion of $36 \%$ scoring at least $1 \mathrm{SD}$ below the population norm is higher than the expected rate of $17 \%$. The same also holds true for the proportion of $21 \%$ of the subjects scoring at least 1 SD below population norms on the WISC-R performance IQ. There is a very similar pattern of findings when children with exposure to nicotine only (IUSE 2) are not excluded from the sample, as shown in table 3.

Various biological risk factors were tested for an association with the outcome parameters. In the case of dichotomous risk factors, analyses had to be restricted to the verbal total IQ and the performance total IQ due to small numbers. It was found that prematurity, low birth weight, and neonatal withdrawal symptoms do not associate with either verbal or performance total IQ. However, as can be seen from table 4 , substance abuse during pregnancy has a significant and negative association with performance total IQ. The association with IUSE is significant even when nicotine (IUSE 2) or the combination 
Table 2. Mean test scale findings, proportion of subnormal scores $(<1 \mathrm{SD})$ and difference from population norms $($ mean $=100, \mathrm{SD}=15)$ in children with IUSE $1(\mathrm{n}=52)$

\begin{tabular}{|c|c|c|c|c|c|c|c|c|}
\hline \multirow[t]{2}{*}{ Test scale } & \multirow[t]{2}{*}{$\mathrm{n}$} & \multirow[t]{2}{*}{ Mean } & \multirow[t]{2}{*}{$\mathrm{SD}$} & \multicolumn{2}{|c|}{ Score $<1$ SD } & \multicolumn{3}{|c|}{ Difference from population } \\
\hline & & & & $\mathrm{n}$ & $\%$ & $\mathrm{t}$ & d.f. & $\mathrm{p}$ \\
\hline Bayley, mental scale & 22 & 88.9 & 9.8 & 7 & 31.8 & -5.30 & 21 & $<0.001$ \\
\hline Bayley, motor scale & 22 & 87.7 & 11.4 & 10 & 45.5 & -5.10 & 21 & $<0.001$ \\
\hline WPPSI verbal IQ & 11 & 91.8 & 14.4 & 3 & 27.3 & -1.88 & 10 & n.s. \\
\hline WPPSI performance IQ & 11 & 90.3 & 14.8 & 4 & 36.4 & -2.19 & 10 & 0.05 \\
\hline WISC-R verbal IQ & 19 & 94.5 & 13.1 & 3 & 15.8 & -1.84 & 18 & n.s. \\
\hline WISC-R performance IQ & 19 & 97.6 & 16.0 & 6 & 31.6 & -0.66 & 18 & n.s. \\
\hline WISC-R total IQ & 19 & 96.0 & 13.7 & 4 & 21.1 & -1.29 & 18 & n.s. \\
\hline Verbal total IQ & 30 & 93.5 & 13.4 & 6 & 20 & -2.65 & 29 & 0.01 \\
\hline Performance total IQ & 30 & 95.0 & 15.7 & 10 & 33.3 & -1.78 & 29 & n.s. \\
\hline
\end{tabular}

IUSE 1: any intrauterine substance exposure.

Table 3. Mean test scale findings, proportion of subnormal scores $(<1 \mathrm{SD})$ and difference from population norms $($ mean $=100, \mathrm{SD}=15)$ in children with IUSE $2(\mathrm{n}=46)$

\begin{tabular}{|c|c|c|c|c|c|c|c|c|}
\hline \multirow[t]{2}{*}{ Test scale } & \multirow[t]{2}{*}{$\mathrm{n}$} & \multirow[t]{2}{*}{ Mean } & \multirow[t]{2}{*}{$\mathrm{SD}$} & \multicolumn{2}{|c|}{ Score $<1$ SD } & \multicolumn{3}{|c|}{ Difference from population } \\
\hline & & & & $\mathrm{n}$ & $\%$ & $\mathrm{t}$ & d.f. & $\mathrm{p}$ \\
\hline Bayley, mental scale & 21 & 89.2 & 9.9 & 6 & 28.6 & -4.96 & 20 & $<0.001$ \\
\hline Bayley, motor scale & 21 & 87.5 & 11.6 & 10 & 47.6 & -4.96 & 20 & $<0.001$ \\
\hline WPPSI verbal IQ & 10 & 91.8 & 15.2 & 3 & 30 & -1.72 & 9 & n.s. \\
\hline WPPSI performance IQ & 10 & 91.0 & 15.3 & 3 & 30 & -1.86 & 9 & n.s. \\
\hline WISC-R verbal IQ & 15 & 92.8 & 13.9 & 5 & 33.3 & -2.00 & 14 & n.s \\
\hline WISC-R performance IQ & 15 & 96.3 & 14.8 & 3 & 20 & -0.98 & 14 & n.s. \\
\hline WISC-R total IQ & 15 & 94.5 & 13.8 & 3 & 20 & -1.55 & 14 & n.s. \\
\hline Verbal total IQ & 25 & 92.4 & 14.1 & 8 & 32 & -2.70 & 24 & 0.01 \\
\hline Performance total IQ & 25 & 94.2 & 14.9 & 6 & 24 & -1.95 & 24 & n.s \\
\hline
\end{tabular}

IUSE 2: any intrauterine substance exposure without considering nicotine as a risk factor.

of nicotine and cannabis (IUSE 3 ) are not considered as risk factors. As table 5 shows, there is a clear detrimental effect of IUSE related to heroin and/or methadone (and further substances except cocaine) even when nicotine or cannabis are controlled for.

All other biological risk factors (e.g. the prenatal, perinatal, and the neonatal risk factors) were correlated with each of the outcome measures, i.e. the various test scores. None of these correlations was significant. Also among the psychosocial risk factors reflecting close social relationships, psychosocial risks, and maternal IQ and education, none of the correlations with child outcome variables was significant.

Children with Intrauterine Exposure to Substances - Developmental Outcome
Given the strongest associations that any outcome measure had with the various risk variables, the performance total IQ was used for multiple regression analyses. Preceding analyses showed that there was a trend $(\mathrm{t}=$ $1.92, \mathrm{p}=0.06)$ for girls to have a higher performance total IQ (mean $=98.7, \mathrm{SD}=14.7)$ than boys (mean $=91.8$, $\mathrm{SD}=13.7)$ and a significant age effect $(\mathrm{F}=4.20$, d.f. $=2$, $\mathrm{p}=0.02$ ) with infants scoring lowest on the Bayley scales (mean $=88.9, \mathrm{SD}=9.8$ ), pre-schoolers scoring in the median range on the WPPSI (mean $=92.3, \mathrm{SD}=15.8$ ), and school-aged children scoring highest on the WISC-R (mean $=101.1, \mathrm{SD}=15.2$ ). Thus, gender and age were considered besides substance abuse during pregnancy in the 
Table 4. Association of verbal and performance IQ with IUSE $(n=38)$

\begin{tabular}{|c|c|c|c|c|c|c|c|c|c|}
\hline & & \multicolumn{4}{|c|}{ Total verbal IQ } & \multicolumn{4}{|c|}{ Total performance IQ } \\
\hline & & mean & $\mathrm{SD}$ & $\mathrm{U}$ & $\mathrm{p}$ & mean & SD & $\mathrm{U}$ & $\mathrm{p}$ \\
\hline \multirow[t]{2}{*}{ IUSE 1} & Present $(\mathrm{n}=30)$ & 93.5 & 13.4 & \multirow[t]{2}{*}{68.5} & \multirow[t]{2}{*}{ n.s. } & 95.0 & 15.7 & \multirow[t]{2}{*}{53.0} & \multirow[t]{2}{*}{0.02} \\
\hline & Absent $(\mathrm{n}=8)$ & 88.0 & 4.0 & & & 109.4 & 9.2 & & \\
\hline \multirow[t]{2}{*}{ IUSE 2} & Present $(n=25)$ & 92.4 & 14.1 & \multirow[t]{2}{*}{148.5} & \multirow[t]{2}{*}{ n.s. } & 94.2 & 15.0 & \multirow[t]{2}{*}{95.0} & \multirow[t]{2}{*}{0.04} \\
\hline & Absent $(\mathrm{n}=13)$ & 92.3 & 7.8 & & & 105.2 & 15.0 & & \\
\hline \multirow[t]{2}{*}{ IUSE 3} & Present $(n=23)$ & 91.0 & 13.7 & \multirow[t]{2}{*}{159.0} & \multirow[t]{2}{*}{ n.s. } & 93.3 & 15.3 & \multirow[t]{2}{*}{93.5} & \multirow[t]{2}{*}{0.02} \\
\hline & Absent $(\mathrm{n}=15)$ & 94.4 & 9.7 & & & 105.1 & 13.9 & & \\
\hline
\end{tabular}

IUSE 1: any intrauterine substance exposure.

IUSE 2: any intrauterine substance exposure without considering nicotine as a risk factor.

IUSE 3: any intrauterine substance exposure without considering nicotine or cannabis as a risk factor.

Table 5. Association of verbal and performance IQ with exposure to heroin and/or methadone

\begin{tabular}{|c|c|c|c|c|c|c|c|c|}
\hline No exposure except nicotine/cannabis $(\mathrm{n}=15)$ & 94.4 & 9.7 & & & 105.2 & 13.9 & & \\
\hline Exposure to heroin/methadone $(\mathrm{n}=13)$ & 91.1 & 6.3 & 30.0 & n.s. & 90.8 & 11.0 & 8.0 & 0.001 \\
\hline No exposure except nicotine $(\mathrm{n}=13)$ & 92.3 & 7.8 & & & 105.2 & 15.0 & & \\
\hline
\end{tabular}

Table 6. Stepwise multiple regression analyses findings of performance IQ on gender, age and intrauterine exposure to substances

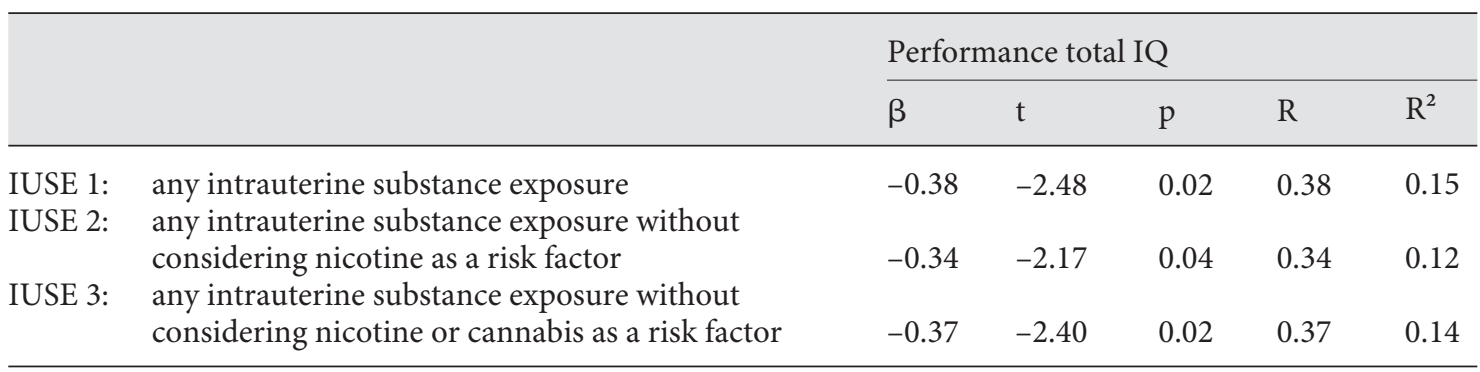

multiple regression analyses. Among these three variables, only IUSE significantly predicted performance total IQ. However, the amount of explained variance amounted to $12-15 \%$ only. Findings for the three different measures of IUSE are shown in table 6.

\section{Discussion}

These findings come from a non-random sample of Swiss children born to substance-dependent mothers who all had been participating in residential programs including both mother and child. A few mothers prema- 
turely terminated the program before final assessments so that there was a small number of missing data for the various tests. However, the present sample certainly is not representative for the majority of very deprived addicts living at the edge of society and imposing a multitude of risks on their offspring. On the contrary, the majority of the mothers in the present study had been sufficiently motivated to enroll as volunteers in a treatment program that addressed the needs of both mothers and their children.

Despite this positive bias, the developmental outcome of the children covering the age range from infancy to preadolescence does not match population norms. Both the mean scores and the proportion of low functioning subjects show that for the majority of developmental outcome scores there is a larger than expected proportion of children who are impaired. This trend is stronger for boys and younger children and in the older children there is also an indication that verbal IQ is affected only.

In general, these findings concur with other studies indicating that on average cognitive function in the offspring of substance-dependent mothers is in the lower normal range $[1-3,5,10,22]$ and that there is a high proportion of children with developmental delays $[4,6,10$, $19,23]$. The lower mean verbal IQ in the combined preschool and school-aged subjects of the present study matches findings of other studies indicating impaired language development predominantly in young children [14-17, 24, 26, 28]. Whether these findings reflect specific prenatal effects on the developing brain remains an open question.

The attempt to isolate relevant predictors of the developmental outcome of the children of substance-dependent mothers resulted only in a few significant findings. From a large list of pre-, peri-, and neonatal risk factors, only intrauterine exposure to substances had a significant association with impaired performance IQ. However, the amount of explained variances was rather small. In the present sample, predominantly heroin or methadone were responsible for this association when controls for nicotine or cannabis consumption were made. The effect of IUSE matches various other study findings $[19,22]$.

In contrast to the conclusion that the subnormal functioning in children of substance-dependent mothers is largely due to low SES or environmental risks $[2,4,18$, 20 ], the present study with a socially less deprived sample found no effect of psychosocial variables or maternal intelligence on outcome of the children. It has to be admitted, however, that maternal IQ was only tested with a very brief assessment so that the assessment may have been lacking sufficient power. In contrast, in the study by Bennet et al. [2] a significant correlation of maternal and child IQ was obtained.

Clearly, there are limitations of the present study. Due to the different, though developmentally appropriate outcome measures, the numbers of subjects in each IQ test group are relatively small. More extended samples may have more power to study the interaction of various risk factors on the development of children with IUSE. Like most studies in the field, data on substance abuse during pregnancy are based on maternal recall so that the duration of time after pregnancy may have precluded some mothers to adequately remember their ingested substances. All these limitations may only be overcome by prospective longitudinal studies including objective measurements of substance exposure by use of urine or meconium.

In conclusion, the present study provides further evidence that the developmental outcome of children of substance-dependent mothers is at risk even in the case of mothers and children who receive intensive intervention by a residential care program.

\section{Acknowledgements}

The author would like to thank all the participating mothers and children of the present study and the two teams of the supporting residential treatment centers, particularly Elisabeth Frei on behalf of 'Die Alternative' and Verena Schäfer on behalf of 'Sozialtherapeutische Gemeinschaft Ruedli'. 


\section{References}

1 Alessandri SM, Bendersky M, Lewis M: Cognitive functioning in 8 - to 18 -month-old substance-exposed infants. Dev Psychol 1998;34:565-573.

$>2$ Bennet DS, Bendersky M, Lewis M: Children's intellectual and emotional-behavioral adjustment at 4 years as a function of cocaine exposure, maternal characteristics and environmental risk. Dev Psychol 2002;38:648658.

3 Singer LT, Arendt R, Minnes S, et al: Cognitive and motor outcomes of cocaine-exposed infants. JAMA 2002;287:1952-1960.

-4 Hurt H, Malmud E, Betancourt LM, Brodsky NL, Giannetta JM: A prospective comparison of developmental outcome of children with in utero cocaine exposure and controls using the Battelle Developmental Inventory. J Dev Behav Pediatr 2001;22:27-34.

$\checkmark 5$ Kilbride H, Castor C, Hoffman E, Fuger KL: Thirty-six-month outcome of prenatal cocaine exposure for term or near-term infants: impact of early case management. J Dev Behav Pediatr 2000;21:19-26.

6 Wasserman GA, Kline JK, Bateman DA, et al: Prenatal cocaine exposure and school-age intelligence. Drug Alcohol Depend 1998;50: 203-210.

7 Griffith DR, Azuma SD, Chasnoff IJ: Threeyear outcome of children exposed prenatally to substances. J Am Acad Child Adolesc Psychiatry 1994;33:20-27.

8 Chasnoff IJ, Griffith DR, Freier C, Murray J: Cocaine/polysubstance use in pregnancy: two-year follow-up. Pediatrics 1992;89:284289.

9 Frank DA, Jacobs RR, Beeghly M, et al: Level of prenatal cocaine exposure and scores on the Bayley Scales of Infant Development: modifying effects of caregiver, early intervention and birth weight. Pediatrics 2002; 110:1143-1152.

-10 Arendt R, Angelopoulos J, Salvatore A, Singer L: Motor development of cocaine-exposed children at age two years. Pediatrics 1999; 103:86-92.

11 Chiriboga CA, Brust JCM, Bateman D, Hauser WA: Dose-response effect of fetal cocaine exposure on newborn neurologic function. Pediatrics 1999;103:79-85.

12 Delaney-Black V: Prenatal cocaine and neonatal outcome: evaluation of dose-response relationship. Pediatrics 1996;98:735-740.

13 Swanson J, Lerner M, March J, Gresham FM: Assessment and intervention for attention-deficit/hyperactivity disorder in the schools - lessons from the MTA study. Pediatr Clin North Am 1999;46:993.
14 Johnson JM, Seikel JA, Madison CL, Foose SM, Rinard KD: Standardized test performance of children with a history of prenatal exposure to multiple substances/cocaine. J Commun Disord 1997;30:45-73.

15 Bender SL, Word CO, DiClemente R, et al: The developmental implication of prenatal and/or postnatal crack cocaine exposure in preschool children: a preliminary report. J Dev Behav Pediatr 1995;16:418-424.

16 Mentis M, Lundgren K: Effects of prenatal exposure to cocaine and associated risk factors on language development. J Speech Hear Res 1995;38:1303-1318.

17 Malakoff ME, Mayes LC, Schottenfield RS: Language abilities of preschool-age children living with cocaine using mothers. Am J Geriatr Psychiatry 1994;2:346-354.

-18 Messinger DS, Bauer CR, Das A, et al: The maternal lifestyle study: cognitive, motor and behavioural outcomes of cocaine-exposed and opiate-exposed infants through three years of age. Pediatrics 2004;113:16771685.

19 Bunikowski R, Grimmer I, Heiser A, et al: Neuro-developmental outcome after prenatal exposure to opiates. Eur J Pediatr 1998; 157:724-730.

20 Ornoy A, Segal J, Bar-Hamburger R, Greenbaum C: Development outcome of schoolage children born to mothers with heroin dependency: importance of environmental factors. Dev Med Child Neurol 2001;43:668675.

21 Grattan MP, Hans SL: Motor behavior in children exposed prenatally to substances; in Chandler LS, Lane SJ (eds): Children with Prenatal Substance Exposure. London, Haworth Press, 1997, pp 89-109.

22 Moe V: Foster-placed and adopted children exposed in utero to opiates and other substances: prediction and outcome at four and a half years. J Dev Behav Pediatr 2002;23. 330-339.

23 Morrison DC, Cerles L, Montaini-Klovdahl L, Skowron E: Prenatally substance-exposed toddlers: cognitive and social development. Am J Orthopsychiatry 2000;70:278-283.

24 Van Baar AL, de Graaff BMT: Cognitive development at preschool age of infants of substance dependent mothers. Dev Med Child Neurol 1994;36:1063-1075.

-25 Chasnoff IJ, Burns KA, Burns WJ, Schnoll $\mathrm{SH}$ : Prenatal substance exposure: effects on neonatal and infant growth and development. Neurobehav Toxicol Teratol 1986;8: 357-362.
26 Rosen TS, Johnson HL: Long-term effects of prenatal methadone maintenance; in Pinkert $\mathrm{T}$ (ed): Current Research on the Consequences of Maternal Substance Abuse. NIDA Res Monogr 59, DHHS Publ No (ADM), 1985, pp 85-1400.

27 Lifschitz MH, Wilson GS, Smith E, Desmond MM: Factors affecting head growth and intellectual function in children of substance addicts. Pediatrics 1985;75:269-274.

28 Kaltenbach K, Finnegan LP: Developmental outcome of children born to methadonemaintained women: a review of longitudinal studies. Neurobehav Toxicol Teratol 1984;6: 271-275.

29 Strauss ME, Lessen-Firestone JK, Chavez CJ, Stryker JC: Children of methadone-treated women at five years of age. Pharmacol Biochem Behav 1979;11:3-6.

30 Schuler ME, Nair P, Kettinger L: Substanceexposed infants and developmental outcome. Effects of a home intervention and ongoing maternal substance use. Arch Pediatr Adolesc Med 2003;157:133-138.

31 Beckwith L, Howard J, Espinosa M, Tyler R: Psychopathology, mother-child interaction, and infant development: substance-abusing mothers and their offspring. Dev Psychopathol 1999;11:715-725.

32 Carta JJ, Atwater JB, Greenwood CR, et al: Effects of cumulative prenatal substance exposure and environmental risks on children's developmental trajectories. J Clin Child Psychol 2001;30:327-337.

33 De Cubas MM, Field T: Children of methadone-dependent women: develop-mental outcomes. Am J Orthopsychiatry 1993;63: 266-276.

34 Bayley N: Bayley Scales of Infant Development, ed 2. San Antonio, Psychological Corporation, 1993.

35 Eggert D: HAWIVA. Hannover-WechslerIntelligenztest für das Vorschulalter. Bern, Huber, 1975

36 Bründler $M$, Schallberger U: HAWIK-R. Hamburg-Wechsler-Intelligenztest für Kinder, Rev 1983. Ergänzungsband zum Handbuch. Bern, Huber, 1988.

37 Oswald WD, Roth E: Der Zahlen-Verbindungstest (ZVT). Ein sprachfreier Intelligenz-Schnell-Test. Göttingen, Hogrefe, 1978.

38 Reitan RM: Trail Making Test: Manual for Administration, Scoring and Interpretation. Indianapolis, Indiana University Press, 1956. 